\title{
Some electrical and magnetic properties of $\gamma-\mathrm{Fe}_{2} \mathrm{O}_{3}$
}

\author{
A VENKATARAMAN \\ Department of Chemistry, Sardar Patel University, Vallabh Vidyanagar 388120 , India \\ MS received 6 May 1991; revised 22 January 1992
}

\begin{abstract}
Fe}_{2} \mathrm{O}_{3}$ synthesized from $\mathrm{FeC}_{4} \mathrm{H}_{4} \mathrm{O}_{4} \cdot 4 \mathrm{H}_{2} \mathrm{O}$ has been studied using various techniques. The phase transformation observed by electrical conductivity measurements agrees well with the initial magnetization measurement. The magnetic hysteresis values compare with those of $\gamma-\mathrm{Fe}_{2} \mathrm{O}_{3}$ samples synthesized using established procedures. $\gamma-\mathrm{Fe}_{2} \mathrm{O}_{3}$ particles obtained were circular in shape showing a well resolved six narrow bands in Mössbauer spectrum. The presence of hydrogen ferrite phase was also confirmed by electrical and magnetic measurements.
\end{abstract}

Keywords. Electrical conductivity; Seebeck coefficient; ferrites; initial magnetization.

\section{Introduction}

$\gamma-\mathrm{Fe}_{2} \mathrm{O}_{3}$ is an important magnetic tape recording material and its synthesis has been studied in some detail (Kuo et al 1982; Karmazsin et al 1983; Ravindranathan and Patil 1986). However, studies on newer methods of synthesis and doping of $\gamma$-Fe $\mathrm{Fe}_{2} \mathrm{O}_{3}$ to improve its magnetic properties are still being actively pursued (Rane et al 1981; Sharrock and Bonder 1985; White 1985; Venkataraman et al 1987a,b; Venkataraman et al 1989) because of its ideal combination of such magnetic hysteresis parameters as saturation magnetization $\left(M_{S}\right)$, coercive force $\left(H_{C}\right)$ and squareness ratio $\left(M_{R} / M_{S}\right)$ (Bate 1975). Pure $\gamma-\mathrm{Fe}_{2} \mathrm{O}_{3}$ is a vacancy-ordered ferrite with a structural formula $\mathrm{Fe}_{8}^{3+}$ $\left[\mathrm{Fe}^{3+} 40 / 3 \square_{1 / 8}\right] \mathrm{O}_{32}$ where $\square$ indicates vacancy sites present in the lattice.

The occurrence of hydrogen ferrite phase with the structural formula $\mathrm{Fe}_{8}^{3+}\left[\mathrm{Fe}_{12}^{3+} \mathrm{H}_{4}^{+}\right]$. $\mathrm{O}_{32}$ has been investigated by Rane et al (1981) and Venkataraman and Mukhedkar (1988) while synthesizing $\gamma-\mathrm{Fe}_{2} \mathrm{O}_{3}$ by thermal decomposition of ferrous oxalate dihydrate and ferrous fumarate half hydrate respectively. The magnetic properties of ferrites in general are influenced by the method of preparation, microstructure and crystal morphology (Schnettler 1972; Bate 1975; Manjula 1990; Vishwanadhan 1990). This paper reports studies on the magnetic behaviour of $\gamma-\mathrm{Fe}_{2} \mathrm{O}_{3}$ obtained by thermal decomposition of ferrous succinate tetrahydrate $\left(\mathrm{FeC}_{4} \mathrm{H}_{4} \mathrm{O}_{4} \cdot 4 \mathrm{H}_{2} \mathrm{O}\right)$, and its suitability as a potent magnetic tape recording material. DC electrical conductivity was studied to understand the irreversible phase transformation $\left(\gamma-\mathrm{Fe}_{2} \mathrm{O}_{3} \rightarrow \alpha-\mathrm{Fe}_{2} \mathrm{O}_{3}\right)$ temperature and the result obtained is supplemented with Seebeck coefficient measurement and magnetic studies. $\gamma-\mathrm{Fe}_{2} \mathrm{O}_{3}$ and other ferrites, apart from their many technological uses, are also useful as potent heterogeneous catalysts.

\section{Experimental}

The experimental procedure for measuring the d.c. electrical conductivity, Seebeck coefficient, initial magnetization with variation of temperature, high field magnetic hysteresis loop tracer (HLT) and Mössbauer parameters were reported earlier (Rane et al 1981). 


\subsection{Synthesis}

$\gamma-\mathrm{Fe}_{2} \mathrm{O}_{3}$ was synthesized using thermal decomposition of $\mathrm{FeC}_{4} \mathrm{H}_{4} \mathrm{O}_{4} \cdot 4 \mathrm{H}_{2} \mathrm{O}$ under a controlled atmosphere of dynamic air containing water vapour at $290^{\circ} \mathrm{C}$ (Venkataraman 1987).

\section{Results and discussion}

Figure 1 shows the plot of $\log \sigma$ vs $1 / T$ for $\gamma-\mathrm{Fe}_{2} \mathrm{O}_{3}$ under static air atmosphere. After the observed maximum $V$, there was a decrease in conductivity $\sigma$ up to $130^{\circ} \mathrm{C}$ as indicated by region $B^{\prime}$. The $\sigma$ value then increased showing a Kink. With further increase in temperature, the $\sigma$ value rose till a phase transformation of $\gamma-\mathrm{Fe}_{2} \mathrm{O}_{3}$ to $\alpha-\mathrm{Fe}_{2} \mathrm{O}_{3}$ was attained with broadening in the curve from the starting temperature $T_{D}$ to the ending temperature $T_{E}\left(T_{D}-T_{E}\right)$. The cooling curve showed hysteresis in which $\sigma$ did not exhibit any variation between $180^{\circ} \mathrm{C}$ and room temperature $\left(30^{\circ} \mathrm{C}\right)$. The occurrence of $V$ was due to the desorption of the adsorbed water molecules and the Kink was due to existence of hydrogen ferrite phase. It is also seen from figure 1 that hydrogen ferrite phase was present up to $190^{\circ} \mathrm{C}$ at which the hydrogen ferrite decomposed to give a vacancy-ordered $\gamma-\mathrm{Fe}_{2} \mathrm{O}_{3}$ i.e. $\mathrm{Fe}_{8}^{3+}\left[\mathrm{Fe}_{12}^{3+} \mathrm{H}_{4}^{+}\right] \mathrm{O}_{32}$ to $\mathrm{Fe}_{8 / 3}^{3+}\left[\mathrm{Fe}^{3+} 40 / 3 \square_{1 / 8}\right] \mathrm{O}_{32}$. This transformation is confirmed by magnetic studies discussed later. On further raising the temperature from $190^{\circ} \mathrm{C}$, there was a slow transformation of $\gamma-\mathrm{Fe}_{2} \mathrm{O}_{3}$ to $\alpha-\mathrm{Fe}_{2} \mathrm{O}_{3}$ as indicated by temperature regions $T_{D}-T_{E}\left(440^{\circ}\right.$ to $\left.530^{\circ} \mathrm{C}\right)$.

The Seebeck coefficient measurements (figure 2) showed a fall in the number of

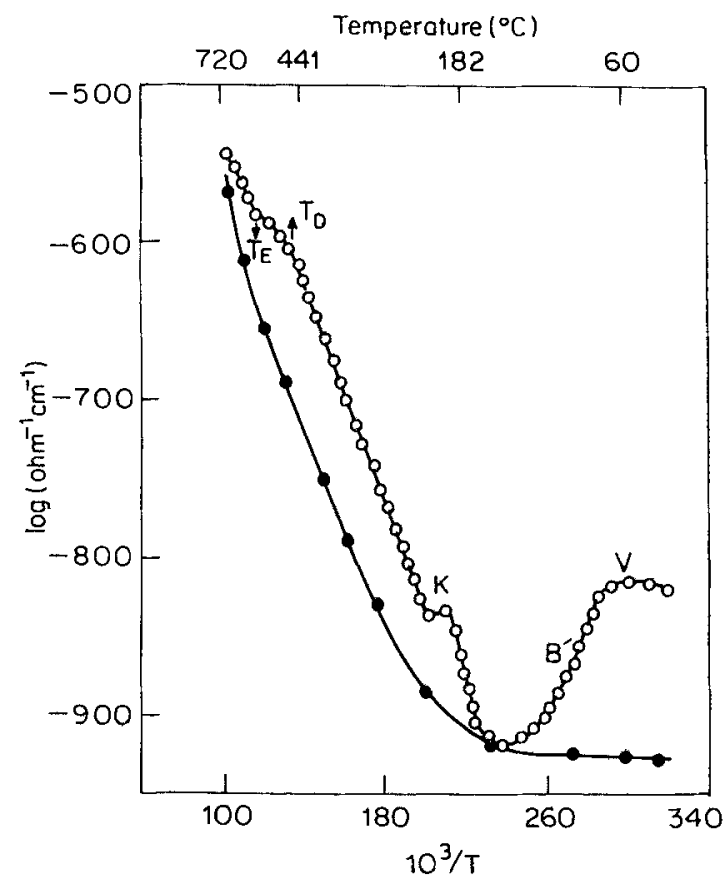

Figure 1. Plot of $\log \sigma$ vs $T^{-1}(\mathrm{~K})$ for $\gamma-\mathrm{Fe}_{2} \mathrm{O}_{3}$ heating curve; $\mathrm{X}$, cooling curve. 


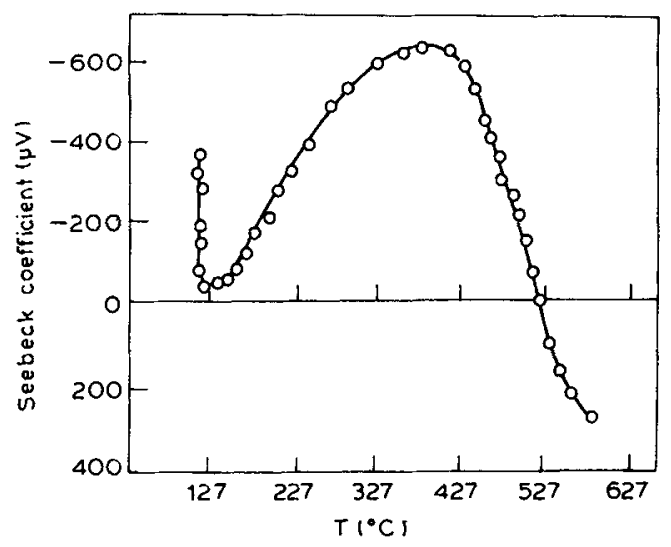

Figure 2. Plot of Seebeck voltage $\left(\mu \mathrm{VK}{ }^{-1}\right)$ vs $T^{-1}\left({ }^{\circ} \mathrm{C}\right)$ for $\gamma-\mathrm{Fe}_{2} \mathrm{O}_{3}$.

Table 1. Magnetic parameters.

\begin{tabular}{lccc}
\hline & $\begin{array}{c}\text { Saturation } \\
\text { magnetization } \\
\left(M_{S} \mathrm{emu} \mathrm{g}^{-1}\right)\end{array}$ & $\begin{array}{c}\text { Coercive force } \\
H_{C} \\
(\mathrm{Oe})\end{array}$ & $\begin{array}{c}\text { Squareness } \\
\text { ratio } \\
\left(M_{R} / M_{S}\right)\end{array}$ \\
\hline Hydrogen ferrite phase & $65 \cdot 0$ & 2500 & 0.53 \\
Vacancy ordered $\gamma-\mathrm{Fe}_{2} \mathrm{O}_{3}$ & $72 \cdot 0$ & $350 \cdot 0$ & 0.58 \\
\hline
\end{tabular}

charge carriers (negative type) in the temperature region $115-145^{\circ} \mathrm{C}$ and then remained almost constant up to $190^{\circ} \mathrm{C}$. A further increase in temperature showed a rise in the number of charge carriers up to phase transformation $(\gamma \rightarrow \alpha)$ temperature, after which the nature of charge carriers changed from negative to positive type.

The magnetic hysteresis parameters for hydrogen ferrite and that of vacancy ordered $\gamma-\mathrm{Fe}_{2} \mathrm{O}_{3}$ (obtained by heating hydrogen ferrite under dynamic nitrogen atmosphere at $200^{\circ} \mathrm{C}$ for $4 \mathrm{~h}$ ) are given in table 1 . The $M_{S}$ value for vacancy ordered $\gamma-\mathrm{Fe}_{2} \mathrm{O}_{3}$ was higher than that observed for hydrogen ferrite. Such behaviour is expected when non-magnetic dopants are present in the crystal lattice (Venkataraman and Mukhedkar 1988). As expected all the magnetic parameters observed compare well with expected values (Bate 1975).

It was believed that permeability $K$ or susceptibility $X_{i}$ of a magnetic material having SD grains always increased on heating and showed a peak (Hopkinson's peak) just before $T_{C}$ and then fell to zero rapidly (Bate 1975; Nagarajan and Murthy 1981). Figure 3 shows the normalized $X_{i}-T$ curve obtained for vacancy ordered $\gamma-\mathrm{Fe}_{2} \mathrm{O}_{3}$. The normalized $X_{i}$ values varied with respect to temperature before Hopkinson's peak indicating SD behaviour of the sample, after this the $X_{i}$ value decreased to zero $T_{C}$ with some tailing.

The Mössbauer spectra of $\gamma-\mathrm{Fe}_{2} \mathrm{O}_{3}$ and that of hydrogen ferrite were found very similar with a well-resolved six narrow lines (half bandwidth of $0.285 \mathrm{mms}^{-1}$ ) in the intensity ratio $3: 2: 1: 1: 2: 3$. This spectra suggested that the effective magnetic fields at $A$ and $B$ sites of $\gamma-\mathrm{Fe}_{2} \mathrm{O}_{3}$ were comparable and the magnetic SD grains were randomly oriented (Venkataraman 1987). The hyperfine field for vacancy-ordered $\gamma-\mathrm{Fe}_{2} \mathrm{O}_{3}$ and hydrogen ferrite phase was found to be $493.8 \mathrm{KOe}$. Hence it can be 


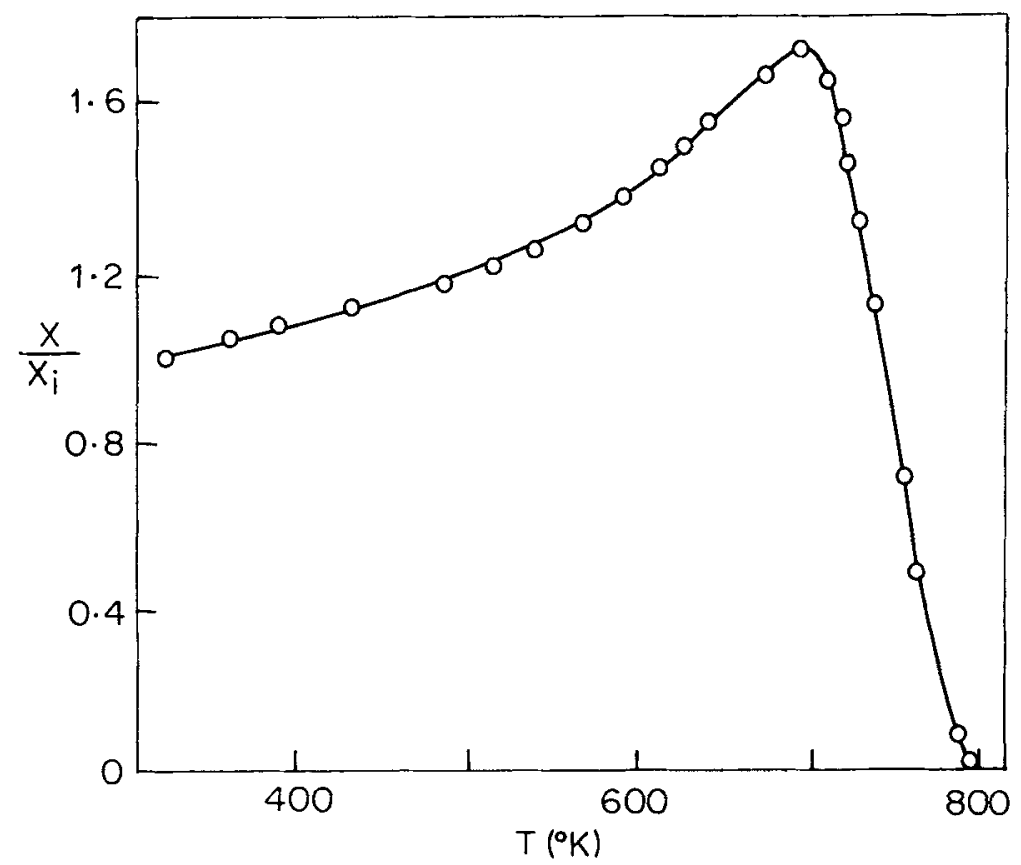

Figure 3. Plot of normalized susceptibility $\left(X / X_{i}\right)$ vs $T\left({ }^{\circ} \mathrm{C}\right)$ for $\gamma-\mathrm{Fe}_{2} \mathrm{O}_{3}$.

stated that the presence of nonmagnetic dopant like $\mathrm{H}^{+}$leading to the formation of hydrogen ferrite does not affect the magnetic fields at $\mathrm{A}$ and $\mathrm{B}$ sites. $\gamma-\mathrm{Fe}_{2} \mathrm{O}_{3}$ thus obtained showed spherical particles bound together to give particles of $1-6 \mathrm{~nm}$ diam. (Venkataraman 1987).

\section{References}

Bate G 1975 in Magnetic oxides (ed.) D J Craik (London: Wiley Interscience) Ch. 12

Karmazsin E, Satre P and Vergnon P 1983 J. Therm. Anal. 28279

Kuo P C, Chang C Y, Wu T S, Chang Y H and Hsu T K 1982 Mater. Sci. Lett. 1137

Manjula R 1990 in Ferrite materials science and technology (eds.) B Viswanadhan and V R K Murthy (New Delhi: Narosa Publishing House) Ch. 2

Nagarajan R and Murthy C R K 1981 Bull. Mater. Sci. 3217

Rane K S, Nikumbh A K and Mukhedkar A J 1981 J. Mater. Sci. 162387

Ravindranathan P and Patil K C 1986 J. Mater. Sci. Lett. 5221

Schnettler F J 1972 in Physics of electronic ceramics Part B (eds) L L Hench and D B Dove (New York: Marcel Dekker) Ch. 25

Sharrock M P and Bonder R E 1985 J. Appl. Phys. 573919

Venkataraman A 1987 In synthesis and properties of $\gamma$-ferric oxide, Ph.D. thesis, University of Poona, Pune.

Venkataraman A, Mukhedkar V A, Rahman M M, Nikumbh A K and Mukhedkar A J 1987a Thermochimica Acta 112231

Venkataraman A, Mukhedkar V A, Rehman M M, Nikumbh A K and Mukhedkar A J 1987b Thermochimica Acta 115215

Venkataraman A and Mukhedkar A J 1988 J. Mater. Sci. 233505

Venkataraman A, Mukhedkar V A and Mukhedkar A J 1989 J. Therm. Anal. 352115

Vishwanadhan B 1990 in Ferrite materials science and technology, (eds) B Vishwanadhan and V R K Murthy (New Delhi: Narosa) Ch. 1

White R M 1985 J. Appl. Phys. 572996 